\title{
Performance of Mahila Mandals of Nehru Yuva Kendra in Tumakuru District-A Comparative Analysis
}

\author{
Sanjay Yadav $^{1}$, V.L. Madhu Prasad ${ }^{2}$ and D. Harshitha ${ }^{2 *}$ \\ ${ }^{1}$ Department of Agricultural Extension, University of Agricultural Sciences, \\ Bengaluru -560065, India \\ ${ }^{2}$ Farmers Training Institute, University of Agricultural Sciences, Bengaluru-560065, India \\ *Corresponding author
}

Keywords

Nehru Yuva

Kendras, Mahila

Mandalsand

Performace

Article Info

Accepted:

05 January 2020

Available Online:

10 February 2020

\section{A B S T R A C T}

The research study was conducted in purposively selected Tumakuru district of Karnataka. Out of 10 taluks, three taluks and two MahilaMandals per taluk were selected based on maximum number of training programmes conducted by NYK making total of six MahilaMandals. Data were collected and analysed by using appropriate statistical tools. The results of the study revealed that majority of MahilaMandals belonged to very good performance category in number of members, selection of group leaders ,attendance of members in meetings, utilization of savings amount (83.33\%),number of meetings conducted (monthly), timings of meetings conducted, knowledge on Mahila Mandals constitutions and bye-laws(100.00\%), repayment of loan barrowed, expansion of entrepreneurial skills ,participation in state and district level Samelanas in every year,training undergone $(50.00 \%)$.With respect tosaving amount, SaraswathiMahilaSamaja stands first with the amount of Rs. 64,800. Among six MahilaMandals, BharathiyaMahilaSamajawas ranked first.With respect to overall performance of taluk wise MahilaMandals, almost equal percent of performance showed by MahilaMandals of Tumakuru(34.59\%) and Tipturtaluk (33.46\%). Only half of the MahilaMandals belonged to high level of performance. Hence, NYKs should concentrate on the rest of half of the members to improve performance by strengthening performance indicators through various extension educational activities.

\section{Introduction}

Almost half of the human resource of the world constitutes women and that is why they influence the growth of nation's economy.In
Indian society, women have a multidimensional role. The largest number of women in India is engaged in farming operations either as cultivators or as supervisors or as agriculture laborers. Active 
involvement of women is very essential for the success of the any community development initiative. This has been proved on many occasions all over the world more so in the developing countries. In agrarian nations such as India, farm women are major producer of food because; agriculture is largely house hold enterprise and they play various roles and work hard to stabilize their family.

A well trained farm woman gives a country enormous potential for economic and social development. It is important that women are viewed as an investment opportunity and are treated as partners in the development process. Proper channelization of this energy and enthusiasm for constructive work in agriculture and rural development can contribute to development of country.

Hence, the concept of MahilaMandal gained significance, especially after 1972 when Nehru Yuva Kendra (NYK) started in India and it started experimenting ensuring the participation of members of MahilaMandals.

The MahilaMandal is defined as a voluntary group valuing personal interactions and mutual aid as a means of altering the problems perceived as alterable and personal by most of its participants. This strategy made a silent revolution in India regarding poverty eradication by empowering the rural women.

MahilaMandals are small groups created for the purpose of enabling members to get economic benefit out of mutual help, empowerment of women and provide employment opportunity. The group basedapproach not only enables the poor women to accumulate capital by way of small savings but also help them to have access to formal credit facilities with subsidiary occupations with the help of NYKs. In general, the
MahilaMandals created were implemented to reach the rural women effectively and help them to obtain easy access to facilities like savings and credit in the long run in alleviating poverty by empowering them, providing knowledge about the various training programmes organised by NYKs and create the employment opportunities.

MahilaMandal under Nehru Yuva Kendra are uplifting its members by means of providing trainings that will enable them to selfemployment such as tailoring, knitting, dress designing, beautification, candle making, mehandi designing, bags making, pot designing, hand embroidery, machine embroidery, fresh flowers making/ bouquet and computer course etc.

The progress of any MahilaMandal depends on the participation of its members in different programmes organised by NYKs and their active involvement in the activities of programs of MahilaMandals and other organizations. With this background the effort was made to know Performance and Comparative AnalysisofMahilaMandals of Nehru Yuva Kendra in Tumakuru District.

\section{Materials and Methods}

The study was conducted in purposively selected Tumakuru district of Karnataka. Out of 10 taluks, three taluks and two MahilaMandals per taluk were selected based on maximum number of training programmes conducted by NYK making total of six MahilaMandals.

The data were collected by using personal interview method with the help of the structured interview schedule and analysed by using Minitab software and the statistical tools like frequency, percentage, mean and standard deviation. 
Table.1 Indicator wise performance of MahilaMandals of NYKs $(n=6)$

\begin{tabular}{|c|c|c|c|c|}
\hline $\begin{array}{l}\text { Sl. } \\
\text { No. }\end{array}$ & Performance Indicators & Category & Groups & Per cent \\
\hline \multirow[t]{2}{*}{1} & \multirow[t]{2}{*}{ Number of members } & Very good (15-20) & 5 & 83.33 \\
\hline & & Good (10-15) & 1 & 16.67 \\
\hline \multirow[t]{2}{*}{2} & \multirow[t]{2}{*}{ Selection of group leaders } & Very good & 5 & 83.33 \\
\hline & & Good & 1 & 16.67 \\
\hline 3 & $\begin{array}{l}\text { Number of meetings } \\
\text { conducted(monthly) }\end{array}$ & $\begin{array}{l}\text { Very good ( } 2 \text { and more } \\
\text { meetings in a month) }\end{array}$ & 6 & 100.00 \\
\hline \multirow[t]{2}{*}{4} & \multirow{2}{*}{$\begin{array}{l}\text { Attendance of members in } \\
\text { meetings }\end{array}$} & Very good $(>90 \%)$ & 5 & 83.33 \\
\hline & & Good $(70 \%-90 \%)$ & 1 & 16.67 \\
\hline 5 & Timings of meetings conducted & $\begin{array}{l}\text { Very good (evening } 4 \text { p.m. } \\
\text { after ) }\end{array}$ & 6 & 100.00 \\
\hline \multirow{3}{*}{6} & \multirow{3}{*}{ Members savings amount } & Very $\operatorname{good}($ Rs. $>37,216)$ & 1 & 16.67 \\
\hline & & Good & 3 & 50.00 \\
\hline & & Unsatisfactory(Rs.<19,050) & 2 & 33.33 \\
\hline \multirow[t]{3}{*}{7} & \multirow{3}{*}{$\begin{array}{l}\text { Accumulated savings of } \\
\text { MahilaMandals }\end{array}$} & Very good (>3lakhs) & 1 & 16.67 \\
\hline & & Good (2-3 lakhs) & 3 & 50.00 \\
\hline & & Unsatisfactory ( $<2$ lakhs) & 2 & 33.33 \\
\hline \multirow[t]{2}{*}{8} & \multirow{2}{*}{ Utilization of savings amount } & $\begin{array}{l}\text { Very good (Fully used for } \\
\text { loaning purposes only) }\end{array}$ & 5 & 83.33 \\
\hline & & Good (other purposes) & 1 & 16.67 \\
\hline \multirow{3}{*}{9} & \multirow{3}{*}{ Repayment of loan barrowed } & Very good (> 55 score) & 3 & 50.00 \\
\hline & & Good (53-55) & 1 & 16.67 \\
\hline & & Unsatisfactory $(<53)$ & 2 & 33.33 \\
\hline \multirow{4}{*}{10} & \multirow{4}{*}{ Maintenance of books/register's } & Very good & & \\
\hline & & & 1 & 16.67 \\
\hline & & Good & 4 & 66.66 \\
\hline & & Unsatisfactory & 1 & 16.67 \\
\hline \multirow[t]{2}{*}{11} & \multirow{2}{*}{$\begin{array}{l}\text { Income Generating activities of } \\
\text { MahilaMandals }\end{array}$} & High ( $>5$ lakhs) & 2 & 33.33 \\
\hline & & Medium (4-5 lakhs) & 3 & 50.00 \\
\hline
\end{tabular}




\begin{tabular}{|c|c|c|c|c|}
\hline & & Low (<4 lakhs) & 1 & 16.67 \\
\hline \multirow[t]{3}{*}{12} & \multirow{3}{*}{$\begin{array}{l}\text { Expansion of Entrepreneurial } \\
\text { skills }\end{array}$} & High & 3 & 50.00 \\
\hline & & Medium & 1 & 16.67 \\
\hline & & Low & 2 & 33.33 \\
\hline 13 & $\begin{array}{l}\text { Knowledge on } \\
\text { MahilaMandals constitutions } \\
\text { and bye-laws (rules and } \\
\text { regulations) for conduct of } \\
\text { day to day business }\end{array}$ & Very good (Known to all) & 6 & 100 \\
\hline \multirow[t]{3}{*}{14} & \multirow{3}{*}{$\begin{array}{l}\text { Knowledge on NYKs } \\
\text { programmes }\end{array}$} & High $(>30.60)$ & 2 & 33.33 \\
\hline & & Medium ( $28.74-30.60)$ & 3 & 50.00 \\
\hline & & Low $(<28.74)$ & 1 & 16.67 \\
\hline \multirow[t]{3}{*}{15} & \multirow{3}{*}{$\begin{array}{l}\text { Credit Facilities availed for self- } \\
\text { employment }\end{array}$} & High ( 4 and more agency) & 1 & 16.67 \\
\hline & & Medium (2-3 agency) & 3 & 50.00 \\
\hline & & Low (<2 agency) & 2 & 33.33 \\
\hline \multirow[t]{3}{*}{16} & \multirow[t]{3}{*}{ Attended inter-state study tours } & High $(>18.03)$ & 2 & 33.33 \\
\hline & & Medium ( $16.31-18.03)$ & 1 & 16.67 \\
\hline & & Low $(<16.31)$ & 3 & 50.00 \\
\hline \multirow[t]{3}{*}{17} & \multirow{3}{*}{$\begin{array}{l}\text { Participation in state and district } \\
\text { level Samelanas in every year }\end{array}$} & High $(>15.18)$ & 3 & 50.00 \\
\hline & & Medium ( $12.82-15.81)$ & 1 & 16.67 \\
\hline & & Low $(<12.82)$ & 2 & 33.33 \\
\hline \multirow[t]{3}{*}{18} & \multirow[t]{2}{*}{ Training undergone } & High $(>37.87)$ & 3 & 50.00 \\
\hline & & Medium ( $33.47-37.87)$ & 1 & 16.67 \\
\hline & & Low $(<33.47)$ & 2 & 33.33 \\
\hline \multirow[t]{3}{*}{19} & \multirow{3}{*}{$\begin{array}{l}\text { Incentives awards to Mahila } \\
\text { Mandals }\end{array}$} & High $(>17.55)$ & 2 & 33.33 \\
\hline & & Medium $(16.45-17.55)$ & 3 & 50.00 \\
\hline & & Low $(<16.45)$ & 1 & 16.67 \\
\hline
\end{tabular}

\section{Results and Discussion}

Indicator wise performance of MahilaMandals of NYKs

The data in Table 1 revealed the indicators namely, number of members, selection of group leaders, number of meetings conducted (monthly), attendance of members in meetings, timings of meetings conducted, members savings amount, accumulated savings of MahilaMandals, utilization of savings amount, repayment of loan barrowed, maintenance of books/register's, income generating activities of MahilaMandals, expansion of entrepreneurial skills, 
knowledge on MahilaMandals constitutions and byelaws (rules and regulations) for conduct of day to day business, knowledge on NYKs programmes, credit facilities availed for self-employment, attended inter-state study tours, participation in state and district level Samelanas in every year, training undergone, Incentives awards to MahilaMandals.

With regard to number of members, 83.33 per cent and 16.67 percent of mahilamandals are belonged to very good and good categories respectively. About 83.33 per cent and 16.67 percent of MahilaMandals belonged to very good and good categories respectively in selection of group leaders.

Cent per cent of MahilaMandals were belonged to very good category respectively in number ( 2 or more meetings in a month) of meetings conducted.

Cent per cent of mahilamandals are belonged to very good category in timings of meeting conducted. Majority $(50.00 \%)$ of mahilamandals belonged to good category followed by unsatisfactory $(33.33 \%)$ and very good $(16.67 \%)$ categories in members saving amount respectively. Further, 50.00 per cent, 33.33 per cent and 16.67 percent of mahilamandals belonged to good, very good and unsatisfactory categories respectively in accumulated savings of mahilamandals. About 83.33 per cent and 16.67 percent of mahilamandals belonged to very good and good categories respectively in utilization of saving amount.

About 50.00 per cent, 33.33 per cent and 16.67 per cent of mahilamandals belonged to very good, unsatisfactory and good categories respectively in repayment of loan barrowed. Majority $(66.6 \%)$ of mahilamandals belonged to good category followed by very good $(16.67 \%)$ and unsatisfactory (16.67\%) categories respectively in maintenance of register's/books.

With respect to income generating activities, 50 per cent of mahilamandals belonged to medium level followed by high (33.33\%) and low $(16.67 \%)$ level categories respectively.

Similarly with regard to expansion of entrepreneurial skills, 50.00 per cent, 33.33 per cent and 16.67 per cent of mahilamandals belonged to high, low and medium level category. Cent per cent of mahilamandals are belonged to very good category in knowledge on mahilamandals constitutions and bye-laws foe conduct of day to day business.

Table.2 Distribution of MahilaMandals of NYKs according to their overall performance $(n=6)$

\begin{tabular}{|c|l|c|r|r|}
\hline Sl. No. & Category & Frequency & Per cent & \\
\hline $\mathbf{1}$ & Low $(<41.93)$ & 1 & 16.70 & Mean $=44.33$ \\
\hline $\mathbf{2}$ & Medium $(41.93-46.73)$ & 2 & 33.30 & \\
\hline $\mathbf{3}$ & High $(>46.73)$ & 3 & 50.00 & S.D. $=4.80$ \\
\hline & Total & 6 & 100.00 & \\
\hline
\end{tabular}


Majority $(50.00 \%)$ of mahilamandals were belonged to medium level of category followed by high (33.33) and low (16.67\%) level of categories respectively in knowledge on NYKs programmes.

About 50.00 per cent, 33.33 per cent and 16.67 per cent of mahilamandals were belonged to medium, low and high level of categories respectively in credit facilities availed for self-employment.

50.00 per cent of mahilamandals belonged to low level category followed by high (33.33\%) and medium (16.67\%) level of categories respectively in attended inter-state study tours.

Nearly 50.00 per cent of mahilamandals were belonged to high level category followed by low (33.33\%) and medium (16.67\%) level categories of participation in state and district level samelanas in every year.
50.00 per cent, 33.33 per cent and 16.67 per cent mahilamandals were belonged to high, low and medium categories respectively in training undergone.

50.00 per cent of mahilamandals were belonged to medium level of category followed by high (33.33) and low (16.67\%) level of categories respectively in incentives awards to mahilamandals. The results were in line with the results of Vaishisht et al., (2008), Verma et al., (2013) andAsha (2015).

\section{Overall performance of MahilaMandals}

It is clear from the result of Table 2 that, 50.00 per cent of mahilamandals belonged to high performance group followed by medium (33.33\%) and low (16.67\%) performance group. These findings are in line with the findings of Vaishisht et al., (2008), and Verma et al., (2013).

Table.3 Comparison of MahilaMandals of NYKs according to their saving amount (Rs.) (n=6)

\begin{tabular}{|c|c|c|c|c|}
\hline Sl. No. & MahilaMandals & $\begin{array}{c}\text { Members savings amount } \\
\text { (Rs.) }\end{array}$ & Per cent & Rank \\
\hline 1 & SaraswathiMahilaSamaja & 64,800 & 38.39 & I \\
\hline 2 & EshwariMahilaSamaja & 24,000 & 14.22 & II \\
\hline 3 & BharathiyaMahilaSamaja & 24,000 & 14.22 & II \\
\hline 4 & SreeJenushreeMahilasangha & 20,000 & 11.85 & III \\
\hline 5 & $\begin{array}{l}\text { Lakshmi ranganathaMahila } \\
\text { Samaja }\end{array}$ & 18,000 & 10.66 & IV \\
\hline 6 & RenukaMahilaMandali & 18,000 & 10.66 & IV \\
\hline
\end{tabular}


Comparison of MahilaMandals of NYKs according to their saving amount (Rs.)

A perusal of Table 3 revealed that, with regard to saving amount, Saraswathi MahilaSamaja ranked first (Rs. 64,800) followed by Eshwari MahilaSamaja and Bharathiya MahilaSamaja both had second position (Rs. 24,000), SreeJenushree MahilaSangha had third position, Lakshmi ranganatha MahilaSamaja and RenukaMahila Mandali both had fourth position respectively.

These findings are in agreement with findings of Suja (2012).
Comparison of MahilaMandals of NYKs according to their expansion of Entrepreneurial skills

Findings from Table 4revealed that, with reference to expansion of entrepreneurial skills, BharathiyaMahilaSamaja ranked first, followed by Lakshmi ranganatha MahilaSamaja and RenukaMahilaMandali had second and third position respectively.

Further, Eshwari Mahila Samaja, Sree Jenushree Mahila Sangha and Saraswathi MahilaSamaja had fourth, fifth and sixth position respectively. These findings are similar to the findings Priyakumari (2015).

Table.4 Comparison of MahilaMandals of NYKs according to their expansion of Entrepreneurial skills $(n=6)$

\begin{tabular}{|c|l|c|c|c|}
\hline Sl. No. & \multicolumn{1}{|c|}{ MahilaMandals } & $\begin{array}{c}\text { Expansion of } \\
\text { Entrepreneurial } \\
\text { skills (Rs.) }\end{array}$ & Per cent & Rank \\
\hline $\mathbf{1}$ & BharathiyaMahilaSamaja & 38,700 & 21.42 & I \\
\hline $\mathbf{2}$ & Lakshmi ranganatha Mahila Samaja & 34,600 & 19.14 & II \\
\hline $\mathbf{3}$ & RenukaMahilaMandali & 33,600 & 18.60 & III \\
\hline $\mathbf{4}$ & SaraswathiMahilaSamaja & 19,400 & 10.74 & VI \\
\hline $\mathbf{5}$ & Sree JenushreeMahila Samaja & 26,300 & 14.55 & V \\
\hline $\mathbf{6}$ & EshwariMahilaSamaja & 28,100 & 15.55 & IV \\
\hline
\end{tabular}

Table.5 Group wise comparison of MahilaMandals of NYKs according to their overall performance $(n=6)$

\begin{tabular}{|c|l|c|c|}
\hline SI. No. & MahilaMandals & Per cent & Rank \\
\hline $\mathbf{1}$ & BharathiyaMahilaSamaja & 19.17 & I \\
\hline $\mathbf{2}$ & EshwariMahilaSamaja & 17.69 & II \\
\hline $\mathbf{3}$ & Lakshmi ranganathaMahilaSamaja & 17.67 & III \\
\hline $\mathbf{4}$ & RenukaMahilaMandali & 15.79 & IV \\
\hline $\mathbf{5}$ & SreeJenushreeMahilasangha & 15.41 & V \\
\hline $\mathbf{6}$ & SaraswathiMahilaSamaja & 14.27 & VI \\
\hline
\end{tabular}




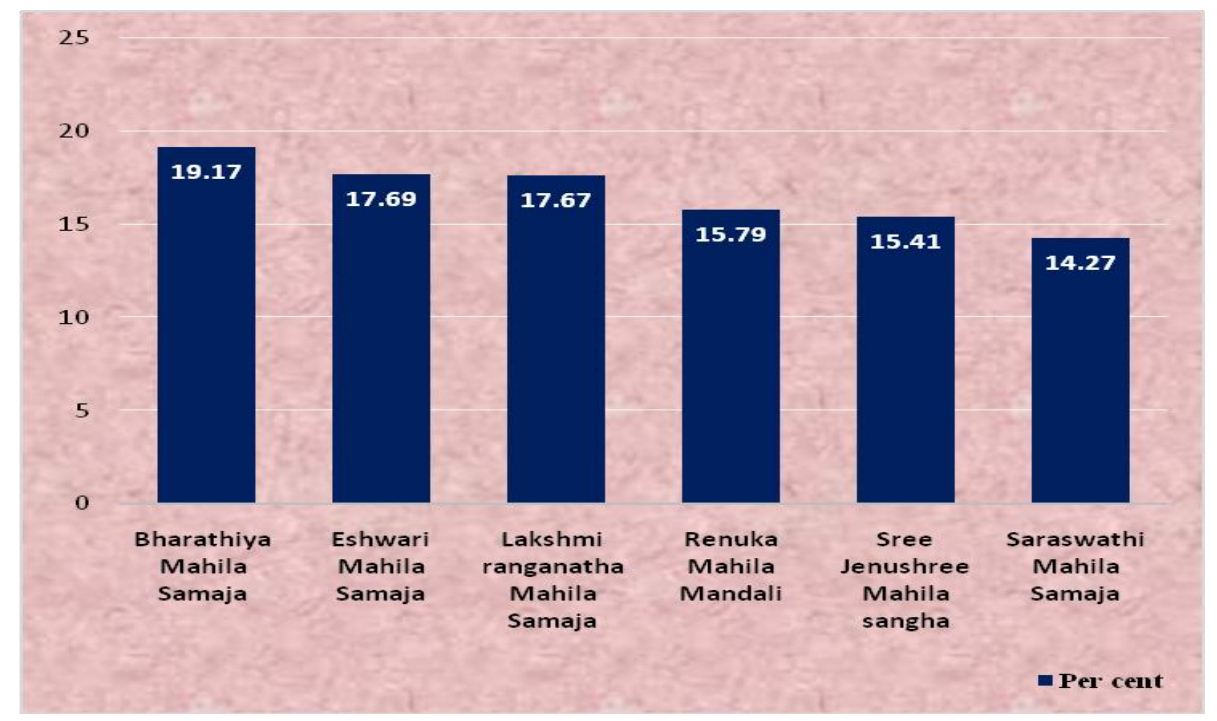

Fig.1 Group wise comparison of MahilaMandals of NYKs according to their

Overall performance

The results from Table 5 and Fig. 1 indicated that out of six Mahila Mandals, Bharathiya Mahila Samaja rank (I), followed by Eshwari MahilaSamaja (II) and Lakshmi ranganatha MahilaSamaja (III) by showing high level of performance.

Further, Renuka MahilaMandali, SreeJenushree MahilaSangha and Saraswathi MahilaSamaja stands fourth, fifth and sixth ranks respectively. The results were in line with the results ofVaishisht et al., (2008) andAsha (2015).
Taluk wise distribution of MahilaMandals of NYKs according to their overall performance

The results from Table 6 revealed that, with regard to overall performance of taluk wise MahilaMandals, 34.59 per cent of performance showed by MahilaMandals of Tumakurutaluk. Further, 33.46 per cent and 31.95 per cent showed by MahilaMandals of Tiptur and Gubbitaluks respectively. The findings are in line with the findings of Verma et al., (2013).

Table.6 Taluk wise distribution of MahilaMandals of NYKs according to their overall performance $(n=6)$

\begin{tabular}{|c|l|c|c|c|}
\hline Sl. No. & Taluks & Frequency & Per cent & \\
\hline $\mathbf{1}$ & Tumakuru & 2 & 34.59 & Mean $=88.50$ \\
\hline $\mathbf{2}$ & Tiptur & 2 & 33.46 & \\
\hline $\mathbf{3}$ & Gubbi & 2 & 31.95 & S.D. $=4.95$ \\
\hline & Total & 6 & 100.00 & \\
\hline
\end{tabular}

It can be concluded from the study results that majority of mahilamandals belonged to very good performance category innumber of members, selection of group leaders ,attendance of members in meetings, utilization of savings amount, number of meetings conducted(monthly), timings of meetings conducted, knowledge on MahilaMandals constitutions and bye-laws, repayment of loan barrowed, expansion of 
entrepreneurial skills, participation in state and district level Samelanas in every year, training undergone.

With respect tosaving amount, Saraswathi MahilaSamaja stands first. Among six MahilaMandals, BharathiyaMahilaSamaja was ranked first. With respect to overall performance of taluk wise MahilaMandals, almost equal percent of performance showed by Mahila Mandals of Tumakuru and Tiptur taluk.Only half of the mahilamandals belonged to high level of performance. Hence, NYKs should concentrate on the rest of half of the members to improve performance by strengthening performance indicators through various extension educational activities.

\section{References}

Asha, K., 2015. A study on the performance of self-help groups (SHGs) in
Ramanagara district of Karnataka. M.Sc. (Agri.) Thesis, Univ. Agri. Sci., Bangalore.

Priyakumari, S.V., 2015. A Comparative study of SHG organized and promoted by SKDRP and Kudumbasree in Dakshina Kannada district and Kollam district, towards empowerment of rural women. [On-line] Available: http://www.sdmcujire.in/userfiles/MRP/M RP_priya\%20kumari.pdf[05 April. 2016].

Suja, S., 2012. SHGs show the way. Glob. Mangt. Rev. 6(3): 20-25.

Vaishisht, S., Khanna, K., Arora, R. and Yadav, N., 2008. Dimensions of Group Dynamics Effectiveness of Self Help Groups of Rural Women in Haryana. Indian Res. J. Extn. Edn. 8(1): 42-45.

Verma, N. K., Pandey, D. K. and Upadhayay, A. D. 2013. Performance

Evaluation of Fishery Based Self Help Groups in West Tripura. J. Extn. Edn.,13(3): 15-18.

\section{How to cite this article:}

Sanjay Yadav, V.L. Madhu Prasad and Harshitha. D. 2020. Performance of Mahila Mandals of Nehru Yuva Kendra in Tumakuru District-A Comparative Analysis. Int.J.Curr.Microbiol.App.Sci. 9(02): 400-408. doi: https://doi.org/10.20546/ijcmas.2020.902.050 